\title{
Investigation into Achaemenid Persian Painted Plasters and Glazed Bricks from Persepolis and Pasargadae in the Smithsonian's Freer Gallery of Art
}

\author{
Emily Aloiz ${ }^{1}$, Janet Douglas ${ }^{2}$, Alex Nagel $^{2}$ \\ 1. Museum Conservation Institute, Smithsonian Institution, Washington, DC, USA \\ 2. Freer Gallery of Art, Smithsonian Institution, Washington, DC, USA
}

Introduction: Architectural fragments of decorated walls, floors and columns excavated from Persepolis and Pasargadae and collected by archaeologist Ernst Herzfeld (1879-1948) are part of the Freer Gallery's Study Collection at the Smithsonian Institution in Washington, D.C. (Fig. 1, 2). There are 40 total fragments of painted earthen plasters and glazed bricks in three boxes labeled FSC-A-1 through FSC-A-3. A technical study of those fragments was undertaken to enhance our knowledge of materials and technology that was used during the Achaemenid Persian Empire (c. 550-330 BCE). Published data on glazed bricks are largely confined to Susa and paint analyses are almost exclusively limited to single layers on stone substrates; even less has been published about earthen and lime plasters. Up to five layers of colored paint exist on the Pasargadae plasters, forming the remnants of a polychrome geometric design that is thought to have decorated the columns of "Palace P" at Pasargadae constructed between c. 545 and 530 BCE [1].

Methodology: Investigation into these materials included comparison of the extant material to images from excavation and notes taken by the excavation team. Elemental analysis of the surface layers was evaluated nondestructively with X-ray fluorescence (XRF), through this form of analysis was limited in the range of elements identified and the layers that could be analyzed. In order to evaluate individual layers of paint and glaze, the fragments were sampled and embedded in epoxy using a method developed by M. Wachowiak [2] (Fig. 3). The polished cross-sections were examined using optical microscopy (Fig. 4), then carbon coated for SEM-EDS analysis.

Conclusions: The earthen plasters from Pasargadae are bound with clay and tempered with an organic material that has since degraded, leaving small holes throughout the plasters. Pigments used to color the paint include Egyptian blue, green malachite, white calcium carbonate, red ocher, red cinnabar and red hematite. Clay was used as a binder for the pink, white and green/gray paint layers; no organic binding media was identified. The fired brick bodies from Persepolis are high silica faience characterized by a lack of aluminum, a technology developed in Egypt that did not use clay. The alkaline glazes all contain lead as a flux and are colored yellow with lead antimonate, gray with magnesium and iron, and green with copper. Lead antimonate was also used as an opacifying agent in the green glazes (Fig. 5). The floor fragments from Persepolis consist of rounded pebbles bound in clay and lime covered by lime plaster and two layers of red hematite paint (Fig. 6). [3]

[1] R Boucharlat in "Herodot und das Persische Weltreich", ed. R Rollinger et al, (Wiesbaden, Harrassowitz) p. 557.

[2] M Wachowiak, Journal of the American Institute for Conservation 42 (2004), p. 205.

[3] The authors would like to thank Blythe McCarthy, Molly McGath, Mel Wachowiak, all of the Smithsonian, and Richard Livingston of the University of Maryland for their invaluable contributions. 

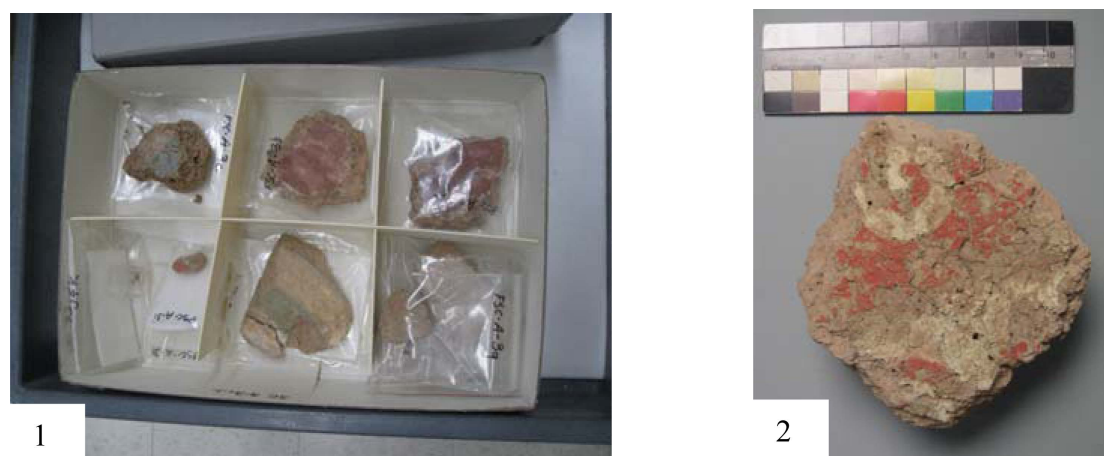

Figure 1. One of 3 (FSC-A-3) boxes containing fragments of glazed bricks and painted plasters from Persepolis and Pasargadae Figure 2. Fragment of painted plaster from Pasargadae (FSC-A-1A).
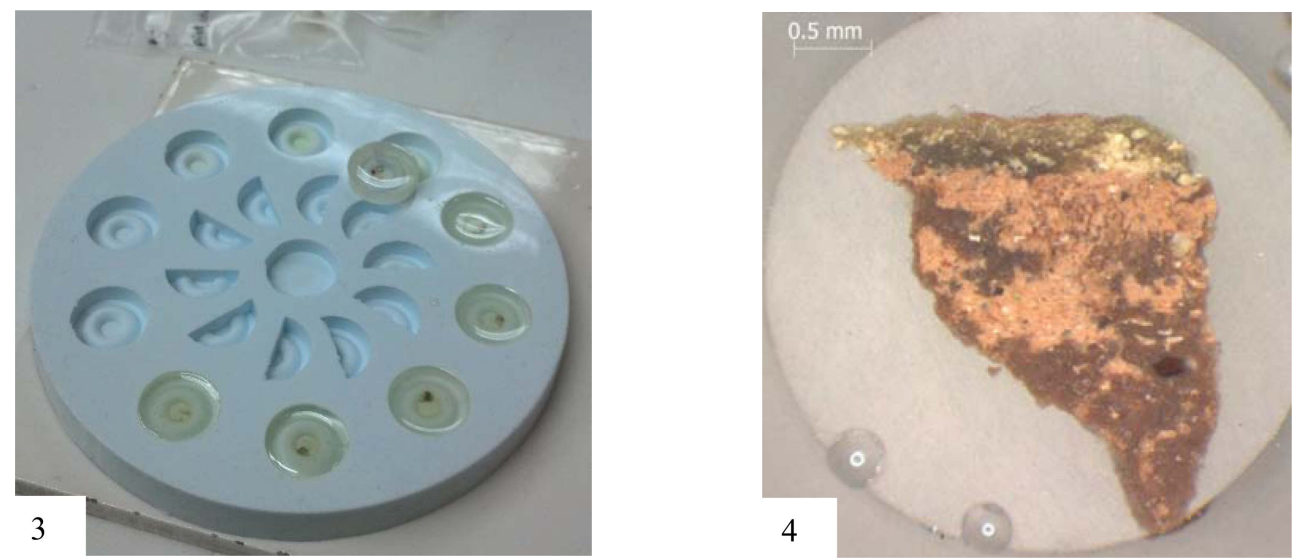

Figure 3. Samples less $3 \mathrm{~mm}$ were embedded in epoxy resin which were polished for optical and SEMEDS analysis in cross-section. Figure 4. Cross-section of a painted earthen plaster shows three layers of paint as well plaster substrate (FSC-A-1I)
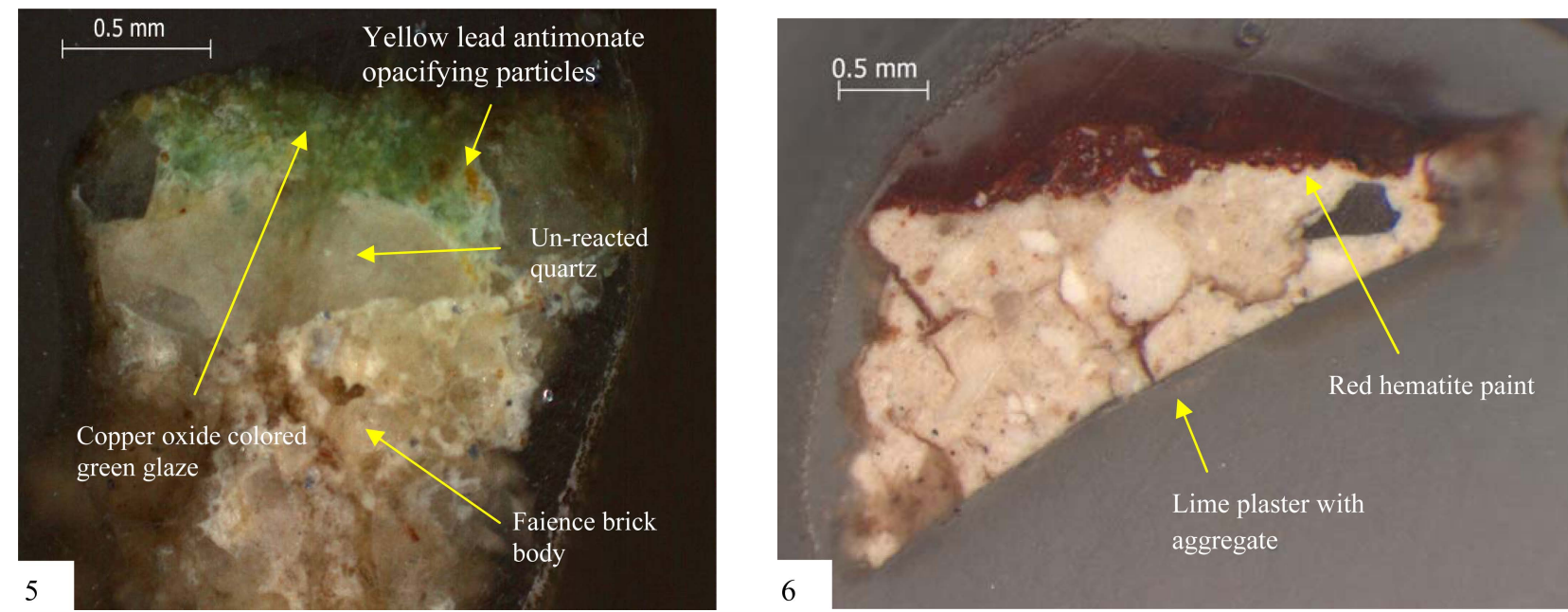

Figure 5. Components identified are labeled on a cross-section of green glazed brick (FSC-A-3D)

Figure 6. Components identified are labeled on a cross-section of floor plaster and paint (FSC-A-3A) 